\title{
Perceived Determinants of Distribution of Counterfeit Drugs in Community Pharmacies, Calabar Municipality Local Government Area, Cross River State, Nigeria
}

\author{
Article by Agada Peter Okpe ${ }^{1,}$ Okareh Oladapo Okareh ${ }^{2}$, Ugobo Emmanuel Eteng ${ }^{3}$ \\ ${ }^{1}$ Senior Pharmacy Specialist, Howard University PACE Center (HU PACE), Strengthening \\ Integrated Delivery of HIV/AIDS Services (SIDHAS) project, Cross River State Office, \\ Calabar, Cross River State, Nigeria \\ E-mail: pagada09@gmail.com \\ ${ }^{2}$ Senoir Lecturer, Dept. of EHS, Faculty of Public Health, College of Medicine, University of \\ Ibadan, Nigeria \\ E-mail: dapsy2001@yahoo.co.uk \\ ${ }^{3}$ Howard University PACE Center (HU PACE), Strengthening Integrated Delivery of \\ HIV/AIDS Services (SIDHAS) project, Cross River State Office, Calabar, Cross River State, \\ Nigeria \\ E-mail:emmanuelugobo@ymail.com
}

\begin{abstract}
Background: The proliferation of counterfeit drugs is of public health concern and worthy of discourse.

Aim: The aim of the study is to assess the perceived factors affecting the distribution of counterfeit drugs in community pharmacies in Calabar municipality.

Methodology: This study is a cross sectional descriptive study that employed the use of closed ended pretested questionnaire for the collection of data. Data was analyzed using the SPSS 20.0.

Results: Findings show that 23(74.2\%) of the respondents were males while 8(25.8\%) were females. Majority of the respondents 28(90.8\%) were community pharmacist, 2(6.5\%) nurses and 1(3.2\%) pharmacy technician. Findings show that about $58 \%$ of purchase of drugs is been determined by the medical/pharmacist representative while $42 \%$ of drugs purchased is been determine by the distributor. Majority of the respondents 19(61.3\%) buy their drugs from medical /pharmacist representative. Respondents were able to detect counterfeit drugs through: customers report (19\%), close scrutiny (32\%), regulatory officials (13\%) and news/company alerts (36\%). Poverty 10(32\%), greed $6(19 \%)$, heavy taxes/VAT on drugs $5(16 \%)$, government policies towards health care delivery $5(16 \%)$, and poor implementation of relevant laws by government agencies 5(16\%) were factors identified as responsible for proliferation of counterfeit drugs.

Conclusion: Poverty is a significant factor responsible for the proliferation of counterfeit drugs. The most common means used by community pharmacists to identify counterfeit drugs are scrutiny and news/alerts. There is need to create more awareness, and seek collaboration with community stakeholders in the fight against counterfeit drugs.
\end{abstract}

Keywords: Counterfeit drugs, community pharmacists, drug distribution

\section{Introduction}

World Health Organization (2010) defined counterfeit drugs as drugs that have been deliberately or not well labeled with respect to identity and or source which makes it difficult to track the manufacturer of such drugs (1). The counterfeited drugs could include incorrect ingredients, misstated amount of the active ingredients, or lack quality control in the manufacturing of the drug. According to NAFDAC Akunyili (2006) in its definition of counterfeit drugs included preparations without active ingredients, preparations that are toxic, expired drugs that are relabeled, drugs issued without 
complete manufacturing information and drugs that are not registered with the National Agency for Food and Drug Administration and Control (NAFDAC) (2).Looking at the above definition, it can be deducted that counterfeit drugs are drugs that are adulterated, inappropriate, and illegal and poses a threat to human health.

The availability of counterfeit drugs in the market presents a serious public health problem, particularly in developing countries such as Nigeria, and may have a significant impact on the national disease and economic burden. It occurs in developing and developed countries (3). Current estimate suggests that $10 \%$ of prescription drugs sold worldwide are counterfeits, fake or contaminated, and in parts of Africa and Asia, the figures exceed 50\% (4).

Counterfeit medicines are widespread and represent a threat to public health which can lead to healthcare failures such as resistance to antibiotics and the spread of disease within a community, as well as loss of life. Research has also shown that poor-quality medicines can reach the market through deliberate fraudulent practices by those that want to get rich overnight. There is low awareness of the problem of counterfeit medicine; a problem that could lead to public-health crisis (5).

Measuring the magnitude of the phenomenon of counterfeit drugs turns out to be extremely complicated, particularly due to various reasons that have to do with the disposable means to detect the trafficking routes, the number and the identity of those involved in the production and distribution processes, and the difficulty in systematizing and coordinating the information from the various stakeholders in charge of keeping, collecting and analyzing data (5).

Available statistics have tried to propose figures on the exact percentage of counterfeit medicines within the worldwide pharmaceutical market. Their estimations reflect both the magnitude and the volatility of the problem. The percentages of counterfeit medicines in different national pharmaceutical markets vary from as 1 percent to as high as 50 percent. In general, higher percentages refer to less developed countries and economies in transition, whereas, lower percentages refer to the developed countries. Therefore, it is essential to take into account geographical, economic, legal and social criteria in order to interpret these percentages (4).

Research has shown that counterfeit medicines is less spread in more developed countries due to a combination of enhanced legislation, stronger institutions and a more efficient regulatory control. According to the WHO, developed countries such USA, Australia, Canada, Japan, New Zealand and those within the European Union (EU) have a very low proportion of counterfeit medicines no more than one per cent of market value (1).

However, the fact that a considerable amount of counterfeit drug cases are declared on an annual basis by developed countries proves that this problem still affects both developed and developing countries. Case studies can illuminate what statistics cannot.

Nevertheless, the situation is more dramatic in less developed countries due to fragile economies, widespread poverty, lack of regulation, difficulties in controlling the system, as well as the difficulties in furthering and enforcing strong legislative measures. WHO estimate shows that counterfeit medicines would represent approximately ten percent of the entire amount of medicines worldwide (1). Pfizer estimates that counterfeit Viagra alone causes a loss of 2 billion USD in sales (ref). According to the centre for medicine in the public interest, based in the United States of America, counterfeit drug sales generated 75 billion USD globally in 2010 (6). The situation seems to be even worse in some African countries.

\section{Methodology}

The research was carried out in Calabar municipality, Cross river state, Nigeria. The study is a community based descriptive study design that assess the determinants of counterfeit medicines. The design was selected for this study because it provided numeric descriptions of the population and described events as they are, as they were or as they will be (7). The target population was owners of community pharmacies in Calabar municipality. The respondents were the community pharmacists or individuals running these community pharmacies. Questionnaire was used for collecting data in this 
study. The primary data was obtained from the questionnaires. The questionnaires contained closeended questions with structured questions. Questionnaires were used because it saves time and confidentiality of information is assured. Pilot study was conducted to test validity and reliability of research instruments, using randomly selected areas outside the study area with similar characteristics.

The data collected was entered in excel environment and exported to SPSS version 22.0 for analysis and was presented in form of frequency tables, statistical tables, charts, and bar graphs (8). Qualitative analysis involved coding and organizing collected data into numerical variables and concepts that address the research questions (9).

Before the commencement of the research, permission was granted from Cross River State Health research ethics committee to carry out the research in the state. During field work, information sheets about the study in Calabar municipality were given out to the respondents, explaining why the research was carried out, by whom, and what it would involve. In community pharmacy outlet, verbal consent from participant was sought before starting the interview and was thanked at the end of the interview. Participants were allowed to withdraw from interview at any time he or she wanted.

Confidentiality of all study participants was assured. Everybody was informed that no names or direct identification made to the questionnaire, except numerical identification number was used for follow up. Before interview, study respondents were requested to participate voluntarily. Respondents were also told of the benefits they will derive from participating in the study

\section{Results}

\section{Socio-demographic characteristics}

Findings show that 23(74.2\%) of the respondents were males while $8(25.8 \%)$ were females. The distribution of marital status shows that majority of the respondents $19(61.3 \%)$ were single while $12(38.7 \%)$ were married. About $97 \%$ of the respondents were Christians with professional distribution of $28(90.8 \%)$ trained community pharmacist, 2(6.5\%) nurses and 1(3.2\%) trained pharmacy technician (table 1.0).

Majority of the respondents were within the age group of $36-40$ years, followed by 26-30 years 7(23\%); 31-35years ;6(19\%), 41-45years, 5(16\%); 46-50years, 3(9.7\%) and 20-25 years 2(7\%);

\section{Determinants and sources of drugs}

Findings show that about $58 \%$ of purchase of drugs is been determined by the medical/pharmacist representative while $42 \%$ of drugs purchased is been determine by the distributor. Majority of the respondents 19(61.3\%) buy their drugs from medical /pharmacist representative, 9(29\%) buy their drugs from the wholesalers, while 2(6.5\%) buy their drugs from open market. Respondents identified patents medicine vendor drug distribution outlets (32.3\%), road side hawkers (35.5\%), approved pharmaceutical shops(16.1\%), and unapproved pharmaceutical shops(9.7\%) as sources of cheap drugs (table 2.0).

\section{Detection of counterfeit drugs and determinants of counterfeit drugs}

Respondents were able to detect counterfeit drugs through: customers report (19\%), close scrutiny (32\%), regulatory officials (13\%) and news/company alerts (36\%) (Table 3.0). Factors responsible for the proliferation of counterfeit drugs includes:poverty 10(32\%), greed 6(19\%), heavy taxes/VAT on drugs 5(16\%), government policies towards health care delivery 5(16\%), and poor implementation of relevant laws by government agencies 5(16\%) (Fig 1.0)

\section{Measures to reduce counterfeit drugs at the community level}

Respondents suggested the following measures to reduce the proliferation of counterfeit drugs at community level: creating awareness on counterfeit drugs (35\%), developing curriculum on how to identify counterfeit drugs by consumers (16\%), seeking collaboration with community stakeholders in the fight against counterfeit drugs (19\%), important information to be readily available to health care 
Texila International Journal of Public Health

Volume 4, Issue 4, Dec 2016

professionals on identification of counterfeit drugs (16\%) and engaging health care professionals in drug counterfeit surveillance (13\%) (table 4.0).

Table 1. Socio-demographic characteristics

\begin{tabular}{|c|c|c|}
\hline Variable & Frequency & Percent \\
\hline \multicolumn{3}{|l|}{ Sex } \\
\hline Male & 23 & 74.2 \\
\hline Female & 8 & 25.8 \\
\hline Total & 31 & 100.0 \\
\hline \multicolumn{3}{|l|}{ Marital status } \\
\hline Single & 19 & 61.3 \\
\hline Married & 12 & 38.7 \\
\hline Total & 31 & 100.0 \\
\hline \multicolumn{3}{|l|}{ Religion } \\
\hline Christian & 30 & 96.8 \\
\hline Others & 1 & 3.2 \\
\hline Total & 31 & 100.0 \\
\hline \multicolumn{3}{|c|}{ Professional qualification } \\
\hline Trained pharmacist & 28 & 90.3 \\
\hline Nurse & 2 & 6.5 \\
\hline $\begin{array}{l}\text { Trained pharmacist } \\
\text { technician }\end{array}$ & 1 & 3.2 \\
\hline Total & 31 & 100.0 \\
\hline \multicolumn{3}{|c|}{ Age distribution of respondents } \\
\hline $20-25 Y r s$ & 2 & 6.5 \\
\hline 26-30Yrs & 7 & 22.6 \\
\hline 31-35Yrs & 6 & 19.4 \\
\hline 36-40Yrs & 8 & 25.8 \\
\hline 41-45Yrs & 5 & 16.1 \\
\hline 46-50Yrs & 3 & 9.7 \\
\hline Total & 31 & 100.0 \\
\hline
\end{tabular}

Table 2. Determinants and sources of drugs

\begin{tabular}{|c|c|c|c|}
\hline Variable & Frequency & Percent & p-value \\
\hline \multicolumn{3}{|l|}{ Determinants of source of drugs } & \\
\hline Distributor & 13 & 41.9 & \multirow[t]{3}{*}{0.369} \\
\hline $\begin{array}{l}\text { Medical/pharmacist } \\
\text { representative }\end{array}$ & 18 & 58.1 & \\
\hline Total & 31 & 100.0 & \\
\hline \multicolumn{4}{|l|}{ Sources of drugs } \\
\hline $\begin{array}{l}\text { Medical/pharmacist } \\
\text { representative }\end{array}$ & 19 & 61.3 & \multirow[t]{5}{*}{0.001} \\
\hline Wholesalers & 9 & 29.0 & \\
\hline open market & 2 & 6.5 & \\
\hline Non response & 1 & 3.2 & \\
\hline Total & 31 & 100.0 & \\
\hline \multicolumn{3}{|c|}{ Where cheap drugs can be bought } & \\
\hline Patent medicine vendor drug & 10 & 32.3 & 0.104 \\
\hline
\end{tabular}




\begin{tabular}{|l|l|l|l|}
\hline distribution outlets & & \\
\hline Road side hawkers & 11 & 35.5 \\
\hline Approved pharmaceutical shops & 5 & 16.1 \\
\hline $\begin{array}{l}\text { Unapproved pharmaceutical } \\
\text { shops }\end{array}$ & 3 & 9.7 & \\
\hline Total & 29 & 93.5 & \\
\hline
\end{tabular}

Table 3.:Detection of counterfeit drugs in community pharmacies

\begin{tabular}{|l|l|l|l|}
\hline \multicolumn{2}{|l|}{ How counterfeit drugs is being detected } & \multirow{2}{*}{ p-value } \\
\hline By customers report & 6 & 19.4 & \multirow{2}{*}{0.238} \\
\hline Close scrutiny & 10 & 32.3 & \\
\hline Regulatory officials & 4 & 12.9 & \\
\cline { 1 - 2 } News/company alerts & 11 & 35.5 & \\
\hline Total & 31 & 100.0 & \\
\hline & & & \\
\hline
\end{tabular}

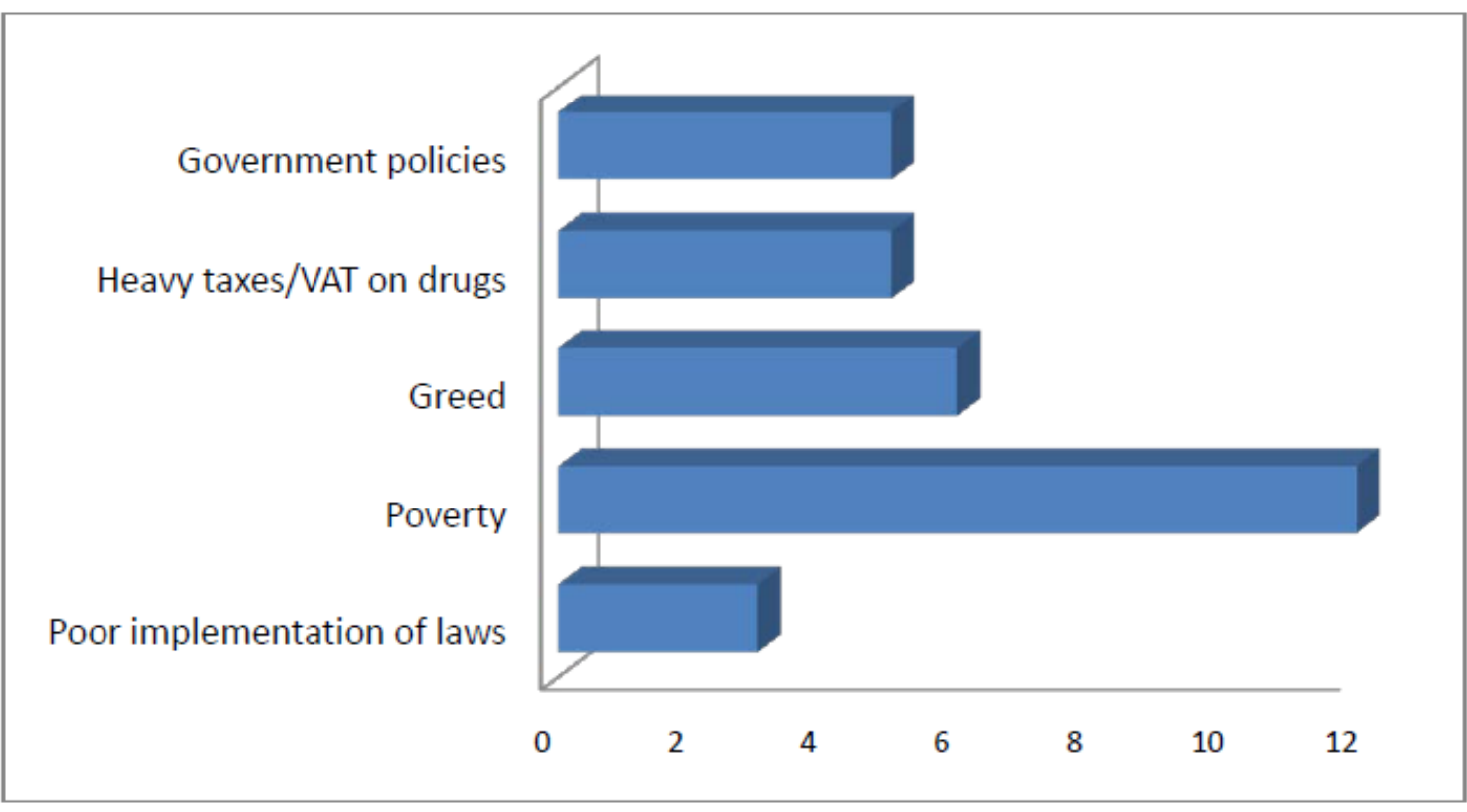

Fig 1.0. Factors responsible for increased growth of counterfeit drugs

Table 4.0. Suggested measures to reduce counterfeit drugs at the community level

\begin{tabular}{|l|l|l|l|}
\hline Variable & Frequency & Percent & P-value \\
\hline Create awareness on counterfeit drugs & 11 & 35.5 & 0.635 \\
\cline { 1 - 3 } $\begin{array}{l}\text { Develop curriculum on how to identify counterfeit } \\
\text { drugs by consumers }\end{array}$ & 5 & 16.1 & \\
\cline { 1 - 2 } $\begin{array}{l}\text { Seek collaboration with community stakeholders in } \\
\text { the fight against counterfeit drugs }\end{array}$ & 6 & 19.4 & \\
\cline { 1 - 2 } $\begin{array}{l}\text { Make important information readily available to } \\
\text { health care professionals on identification of } \\
\text { counterfeit drugs }\end{array}$ & 5 & 16.1 & \\
\cline { 1 - 2 } $\begin{array}{l}\text { Engage health care professionals in drug } \\
\text { counterfeit surveillance }\end{array}$ & 4 & 12.9 & \\
\cline { 1 - 2 } Total & 31 & 100.0 & \\
\hline
\end{tabular}


Texila International Journal of Public Health

Volume 4, Issue 4, Dec 2016

\section{Discussion}

Counterfeit pharmaceuticals remain one of the world's fastest growing industries. Recent trends suggest an increase in counterfeit drug sale to over $\$ 70$ billion in 2010 , an increase of over $90 \%$ from 2005. A report by Pfizer, a global pharmaceutical firm, on counterfeit drugs states that profits from counterfeiting today surpasses gains made from heroin and cocaine (10).

Findings from this study shows that majority of the respondents (61\%) source their drugs from medical /pharmacist representative, 29\% source their drugs from the wholesalers, and only $6.5 \%$ source their drugs from open market, which is similar to findings from a study carried out by Odiliet.al, (2006) (11). The study revealed that majority of the respondents claimed they sourced their drug products personally from wholesalers. For respondents that buy their drugs from the wholesalers, there is much concern about where the wholesalers get their drugs. There is available evidence that major pharmaceutical distributors and even medical representatives dump their products in unlicensed open markets in order to meet sales targets and make quick turnover(2)

Respondents were able to detect counterfeit drugs through: customers report (19\%), close scrutiny (32\%), regulatory officials (13\%) and news/company alerts (36\%). This finding is very encouraging as it suggests that the respondents are aware of the occurrence of counterfeit drugs and are encouraged to check for drug security measures in order to identify such counterfeit drugs. However, it is important to note that fake and counterfeit drug detection, using only visual inspection is not full proof and so is unreliable except when the suspected drug is from unsophisticated forgers.

Factors such as weak legal framework, consumers' attitude towards counterfeit medicines and higher prices charged on imported drugs encourage the proliferation of counterfeit drugs (6).

In developed countries, minimal or no tariffs are charged on pharmaceutical products $(2,13)$. This is markedly different in less developed nations where high taxes and tariffs are usually charged on genuine medicines, thereby resulting in eventual escalation in drug prices, diminution in incentive to adequate supply of drugs and resulting in scarcity of the drugs that may be exploited by the counterfeiters (12).

According to Olusegun (2013) (10), greed, ignorance and corruption are other factors contributing to the prevalence of fake drugs in Nigeria. Corruption and greed is seen from the drug regulating authorities and the drug importers and manufacturers. The effectiveness of regulatory bodies is negatively affected by the high level of official manipulations and corruption in the Nigerian healthcare system. It is common knowledge that the law enforcement agencies are paid off to look the other way, while the business of fake drugs flourishes. Corruption and conflict of interest are the driving forces behind poor drug regulation, which directly encourages drug counterfeiting (14).

\section{Conclusions/recommendations}

Poverty is a significant factor responsible for the proliferation of counterfeit drugs. The most common means used by community pharmacists to identify counterfeit drugs are scrutiny and news/alerts. Community pharmacists and other allied health professionals should well trained on how to identify counterfeit drugs.

There is need to create more awareness on counterfeit drugs, and seek collaboration with community stakeholders in the fight against counterfeit drugs.

It is also important to implement regulatory measures which should be complemented by efforts to minimize drug diversion and strengthen communication between manufacturers, providers, and regulatory authorities (15).

\section{Limitations of the study}

This study had the following limitations which should be addressed in future research. One of its limitations is that of history as respondents may not recall all the information in the past due to loss of memory. This study is limited by the inability of respondents to identify counterfeit drugs by chemical 
method. Other professionals, other than community pharmacist were involved in this study which makes it difficult to generalized the study to community pharmacist.

\section{References}

[1]. World Health Organization (2012). Substandard and counterfeit medicines. Fact sheet No. 275, 2012. Available at http://www.who.int/mediacentre/factsheets/2012/fs275/en/ (last accessed 6 ,march 2016).

[2]. Akunyili DN (2006). Strategies employed in combating drug counterfeiting in Nigeria. A paper presented at the WHO Workshop in collaboration with Italian Medicines Agency and The International Federation of Pharmaceutical Manufacturers and Associations, Held in Rome, Italy $15^{\text {th }}-18^{\text {th }}$ Feb. 2006

[3]. Lewis, K. (2009). The fake and the fatal: the consequences of counterfeits. The Park Place Economist, XVII, 47-58.

[4]. Newton PN, Lee SJ, Goodman C, Fernández FM, Yeung S, Phanouvong S, Kaur H, Amin A, Whitty C, Kokwao G, Lindegardh N, Lukulay P, White L, Day N, Green M, White N (2009) Guidelines for field surveys of the quality of medicines: a proposal. PLoS Med 6

[5]. Charles Clift (2010). Combating counterfeit, falsified and substandard medicines: defining the way forward? centre on global health security, ghbp 2010/01

[6]. Opiyo, J.K. (2006). Responses of pharmaceutical firms to the challenges of illegal imports. Nairobi: Nairobi University.MBA Thesis.

[7]. Oso ,W.Y \&Onen, D. (2009). Writing Research Proposal and Report. Nairobi: Sitima

[8]. Chambers, R. L., \& Skinner, C. J. (Eds.). (2003). Analysis of survey data. John Wiley \& Sons.

[9]. Mugenda, O. M. \&Mugenda, A. G., (2003), Research Methods; Quantitative and Qualitative Approaches, Acts Press, Nairobi, Kenya

[10]. Olusegun Akinyandenu (2013). Counterfeit drugs in Nigeria: A threat to public health. African Journal of Pharmacy and Pharmacology 7(36), pp. 2571-2576, academicjournals.org/AJPP

[11]. Odili, Valentine U., Osemwenkha Sylvia, Eke Esther U. and Okeri Henry A (2006). Identification of Counterfeit Drugs by Community Pharmacists in Lagos State. Tropical Journal of Pharmaceutical Research, 5(1), pp. 545-550

[12]. Morris, J., \& Stevens, P. (2006). Counterfeit medicines in less developed countries. London: International Policy Network, May, 3, 6.

[13]. Harris, J., Stevens, P., \& Morris, J. (2009). Keeping it real: Combating the spread of fake drugs in poor countries. International Policy Network

[14]. Akiny, O. (2013). Counterfeit drugs in Nigeria: A threat to public health. African Journal of Pharmacy and Pharmacology, 7(36), 2571-2576.

[15]. Fadlallah, R., El-Jardali, F., Annan, F., Azzam, H., \&Akl, E. A. (2016). Strategies and Systems-Level Interventions to Combat or Prevent Drug Counterfeiting: A Systematic Review of Evidence Beyond Effectiveness. Pharmaceutical Medicine, 30(5), 263-276. 